\title{
The Embryonic and Postembryonic Development of the Ultimobranchial Body of the Hamster (Cricetus auratus)-in Relation to the Differentiation of the Parafollicular Cells
}

\author{
By \\ Isamu Takagi, Keiki Yamada \\ and Shooichi Sugiyama \\ Department of Anatomy, School of Medical Technology and Nursing, \\ and Department of Anatomy, School of Medicine University \\ of Fujita Gakuen Toyoake City, Aichi Prefecture, Japan \\ -Received for Publication, October 3, 1973-
}

The data that the parafollicular cells develop from the thyroid follicle cells (Nonidez, 1932a, b, 1933 ; Raymond 1932 ; Sugiyama, 1954) are no longer tenable at the present time. They have been found to be of ultimobranchial origin (Godwin 1936/37; Sato, 1959; Ishikawa, 1965 ; Pearse et al. 1967). With recent experiments which suggest a possibility of thyroid origin or parathyroid origin for calcitonin that lowers blood calcium in mammals, the problem of responsibility of the parafollicular cells for secretion of this hormone has received much attention. On the other hand, the ultimobranchial body itself has been reported to be one of the vital endocrine members of calcium metabolism in lower vertebrates. The extracts obtained from ultimobranchial bodies of fishes, amphibians, reptiles and birds have been found to have hypocalcemic activity (Copp et al. 1967, 1968; Moseley et al. 1968). This fact develops from a number of basic studies (Matsuzawa 1966, Matsuzawa et al. 1967, Young et al. 1968) of parafollicular cells responsible for secretion of the calcitonin.

The aim of the present paper is to give fundamental data as a basis to the problem of the histological development of ultimobranchial body in relation to the parafollicular cells, by using hamsters which have been relatively rarely examined for such a kind of investigation.

\section{Material and Methods}

Materials consisted of developing pharynges including thyroid glands of 1) hamster embryos varying in age from 9 to 15 days of 
gestation and 2) postnatal hamsters of different ages from immediately after birth to young adult. Intrauterine ages of the hamster embryos were estimated by measuring the length of days after overnight placing together of estrous males and females in cages, combining with an examination of vaginal smears of female hamsters in every morning. The presence of sperm in the smear in the morning (9:00 AM) was considered to be the beginning of gestation. Twenty-four hours after sperm were found were regarded as one day of gestation. The embryos were collected at almost daily intervals between 9 days of gestation and full term.

The embryos were fixed in toto chiefly in Zenker-formol fluid and some of them in Carnoy fluid, embedded in paraffin, sectioned at 6 to $8 \mu$ serially transversely or sagittally and stained with Hansen's hematoxylin and eosin. The postanatal hamsters were sacrificed at one and two days of age soon after birth and at two or three day intervals after 30 days. At least, three to 5 animals were use for each age group. In these animals, the entire pharyngeal regions removed from the necks were treated in the same manner and frequently fixed in Kolster fluid and stained with Heidenhain's iron hematoxylin.

\section{Observations}

Embryonic Life-9 days of gestation $3 \mathrm{~mm}$ CRL

Ultimobranchial bodies appeared as a round to semilunar epithelial pocket in sagittal section, in the form of the 4 th pharyngeal pouch, developing from the primitive pharynx (Fig. 1). The third pharyngeal pouch was situated already in the front of the ultimobranchial bodies. The ultimobranchial bodies were averagely $75 \mu$ in the craniocaudal diameter $120 \mu$ in the transverse diameter and $87 \mu$ in the ventrodorsal diameter. Between the third pharyngeal pouch and the ultimobranchial body, the 4 th branchial arch artery, very widely dilated and running from the aortic sac to the dorsal aorta, was found (Fig. 1). Behind the ultimobranchial bodies the 6 th branchial arch artery was well seen (Fig. 1).

The ultimobranchial bodies were situated dorsocaudally far from the thyroid primordium placed upon the branching point of the Truncus arteriosus. The ultimobranchial bodies consisted of multicell-layered epithelium (Figs. 1 and 2). The epithelial cells lining directly the cavity were cubical to columnar. They contained often a few to several metachromatic karyolytic droplets of varying sizes (Fig. 2). The nuclei were round to oval, and uniformly of almost the same size-averagely 6 to $7 \mu$ in the long diameter and 6 to $5 \mu$ in the short diameter. The chromatin reticulums were faintly stained. 
The nuclei were often in mitotic division (Fig. 2). The cytoplasm was faintly eosinophilic and finely granular. The cell boundaries were relatively distinct.

The cavity of the ultimobranchial bodies was also round to semilunar and contained a little amount of eosinophlic substance.

Mesenchymal tissue surrounding the ultimobranchial bodies was loose and not arranged in layers (Fig. 2).

10 days of gestation $5 \mathrm{~mm}$ CRL

The ultimobranchial bodies were usually situated in almost the same level as found before (Fig. 3). Between the third pharyngeal pouch and the ultimobranchial body, the 4th branchial arch artery, better developing, and behind the ultimobranchial body, the 6th branchial arch artery, more grown, were found.

The ultimobranchial bodies grew in size and $125 \mu$ in the craniocaudal diameter $96 \mu$ in the transverse diameter and $112 \mu$ in the ventrodorsal diameter. Their epithelial wall became thick and multicell-layered. The epithelial cells contained abundantly metachromatic karyolytic round particles of varying sizes (Figs. 3 and 4). The cell boundaries were relatively distinct. The nuclei were round to oval and of almost the same sizes as before-6 to $7 \mu$ in the long diameter and 5 to $6 \mu$ in the short diameter-and located in the outer zone of the epithelium. They are often in mitotic division (Fig. 4).

The cavity of the ultimobranchial bodies contained no substance.

Around the ultimobranchial bodies, mesenchymal tissue became denser in arrangement than before.

11 days of gestation

The neighboring branchiogeneous primordia including the thyroid primordium showed marked histological and topographic changes in this stage. The thyroid primordium rided as a transverse body with developing lobes upon the Truncus arteriosus (Figs 5 and 7). Behind the lobes, the primitive common carotid arteries were found.

The third branchial pouch became divisible into two distinct primordia, parathyroid (3) and thymic (3), and was located lateral to the common carotid artery. The parathyroid (3) primordium was cranial while the thymic (3) primordium was better growing and became a long caudal body which was extending towards the heart.

The ultimobranchial bodies separated from the primitive pharynx and appeared usually as an ovoid body- $112 \mu$ in the craniocaudal diameter, 100 to $125 \mu$ in the ventrodorsal diameter and $70 \mu$ in the transverse diameter, and were located just behind the dorsal zone of the cranial part of the thyroid lobe and further medial to the Arcus aortae and A. subclavia (Fig. 7). The epithelial wall remained still 
multi-cell-layered. The epithelial cells contained metachromatic karyolytic particles as abundantly as before (Fig. 6). The nuclei were round to oval and were located in the outer zone of the wall and were uniformely of almost the same size, generally 6 to $7 \mu$ in the long diameter and 5 to $6 \mu$ in the short diameter. Their chromatin reticulums were faintly stained. The cytoplasm was moderately eosinophilic and granular.

12 days of gestation

The ultimobranchial bodies generally appeared as a slightly irregular shaped, thick-walled ovoid cyst medial to the thyroid lobe$75 \mu$ in the craniocaudal diameter $68 \mu$ in the transverse diameter and $150 \mu$ in the ventrodorsal diameter, and were being incorporated within its dorsal zone (Fig. 8). The parathyroid primordium (3) became located lateral to the thyroid lobe and medial to the common carotid artery.

The ultimobranchial bodies, as a whole, were stained more faintly than thyroid primordial tissue. The epithelial cells of the wall were arranged in several cell layers, and those lining the cavity were cubical to columnar. The nuclei were round to oval and 6 to $7 \mu$ in the long diameter and 5 to $6 \mu$ in the short diameter. Metachromatic karyolytic particles-degenerative figures were slightly decreased, while mitotic figures were increased in number. The cytoplasm was more faintly eosinophilic than that of thyroid primordial tissue.

In this stage, some of ultimobranchial bodies began to extend epithelial cell masses from its wall (Fig. 8 arrow). The epithelial cell masses were found between surrounding thyroid primordial tissues and were often in direct fusion with them. Their epithelial cells were polygonal in shape. Some of the nuclei were slightly larger than those of the epithelial cells lining the cyst cavity and larger than those of thyroid primordial cells. The thyroid primordial tissue was producing radial cell arrangements with central splits, and cell cords. The nuclei of thyroid primordial cells were slightly richer in chromatin amount and smaller in size.

13 days of gestation

Thyroid primordial tissue became primitive follicular tissue and increased in number-radial cell arrangement with a central intercellular cavity (primitive follicles)-increased markedly. Between primitive follicular tissues, sinusoidal capillaries were seen.

The ultimobranchial bodies were completely incorporated as an ïrregular-shaped cyst within the dorsomedial zone of the middle onethird of the thyroid lobe. They were averagely $150 \mu$ in the craniocaudal diameter, 112 to $62 \mu$ in the ventrodorsal diameter and 87 to $75 \mu$ in the transverse diameter. The epithelial cells of the cyst wall 
were arranged in a few cell layers. Those lining the cavity directly were cubical to columnar. The nuclei were of varying sizes. The cytoplasm was faintly stained than that of primitive follicle cell. Metachromatic chromatin particles were decreased in number while mitotic figures were frequently found. The cavity contained a little amount of cell detrituses.

Some of the ultimobranchial bodies appeared as a long oval multicell-layered cyst with a split-like cavity. From their epithelial wall, epithelial cell masses were extending between surrounding primitive follicular tissues and fused directly with them. Here, some of the nuclei were larger than those of primitive follicle cells and their chromatin reticulum was faint and loose.

14 days of gestation

In the thyroid primordium, primitive follicles increased in number. Some of the primitive follicles acquired a distinct central tiny cavity which contained faintly stained homogeneous material-colloid. The nuclei of primitive follicle cells became further smaller than before and richer in chromatin. Some of interfollicular capillaries remained still sinusoidal.

The ultimobranchial bodies generally remained in almost the same situation as before but were found as an incorporated irregularshaped growing cyst (Fig. 9). They were $144 \mu$ in the craniocaudal diameter, $125 \mu$ in the ventrodorsal diameter and $112 \mu$ in the transverse diameter. The epithelial cells of the cyst wall revealed no marked change. The epithelial cells lining directly the cavity were cubical to columnar. Their nuclei were 5 to $6 \mu$ in the long diameter and 5 to $6 \mu$ in the short diameter and were as large as or slightly larger than in size those of primitive follicle cells (Fig. 10). Metachromatic karyolytic chromatin particles were decreased bere while mitotic figures appeared frequently (Fig. 10). The cavity contained rarely cell detrituses.

From the epithelial wall, epithelial cell masses were extending between thyroid follicular tissues (Figs. 9 and 10). Some of them began to separate from the epithelial wall. The nuclei and cell bodies of the epithelial cell masses were usually larger than those of primitive follicle cells. The nuclei were 6 to $8 \mu$ in the long diameter and 5 to $6 \mu$ in the short diameter. The cytoplasm was faintly eosinophilic.

15 days of gestation

The thyroid primordium in this stage consisted of matured but small follicles, and all of the follicles contained eosinophilic colloid (Fig. 11). 
The ultimobranchial bodies generally appeared as an irregularshaped cyst within the dorsomedial zone of the middle one-third of the thyroid lobe (Fig. 11). Some of them appeared within the dorsolateral zone. Three diameters, craniocaudal, transverse and ventrodorsal, were variable. Some were $75 \mu$ in the ventrodorsal diameter and $125 \mu$ in the transverse diameter.

The epithelial cells of the cyst wall began to reveal a histological change in the nuclei and cell bodies in this stage. The epithelial cells lining directly the cavity of the cyst were generally cubical, but they were sometimes squamous or markedly swollen and rarely ciliated (Fig. 12). The nuclei of the epithelial cell were as large as those of follicle cells or somewhat larger in size and had more faintly stained chromatin reticulums. Their mitotic figures were still frequently seen. The cytoplasm was more faintly stained than that of follicle cells.

In epithelial cell masses deriving from the cyst wall, some of the nuclei were larger than those of follicle cells (Figs. 11 and 12). They were 6 to $8 \mu$ in the long diameter and 5 to $6 \mu$ in the short diameter. The epithelial cells with such a larger nucleus were contained within the cyst wall or separated from the epithelial cell masses and were found singly or in groups further between follicles and directly upon follicles-in interfollicular and parafollicular positions.

Postnatal life-The ultimobranchial bodies ranging in age from immediately after birth to 60 days were uniformly found as an irregular-shaped cyst with more or less marked production of epithelial cell masses extending from the cyst wall (Figs. 13 and 14). They were located in the dorsomedial zone or in the central zone, rarely in the dorsolateral zone of the middle or lower one-third of the thyroid lobe.

The cavities were usually split-like and contained generally no secretory substance, but sometimes eosinophilic, homogeneous partly vacuolated substance with or without cell detrituses.

In adults, the main original cyst, with communicating and noncommunicating accessory cysts-multilocular cysts appeared as the residual ultimobranchial body and their contents were almost similar in appearance to those of the main cavity (Fig. 16).

The epithelial cells of the cyst wall were usually arranged in single and double, rarely stratified cell layers. Those lining directly the cyst cavity were generally cubical or squamous and sometimes darkly stained (Figs. 14 and 15). Towards puberty, some became clearly swollen and others became ciliated cells or rarely goblet cells. Underlying epithelial cells were polygonal and moderately stained. The nuclei were round to oval and as large as or smaller than those of thyroid follicle cells. The chromatin reticulums were moderately dense, but sometimes invisible due to homogeneous dark staining of 
the nuclei. The cytoplasm was moderately eosinophilic and sometimes darkly stained. In some of the epithelial cells, especially in those lining the cavity directly, the cytoplasm was variable in staining from intensely dark to clearly swollen in iron-hematoxylin stain.

Epithelial cell masses deriving from the cyst wall were variable in development and in amount from individual to individual. In some of the ultimobranchial bodies, they were scarcely visible and lessdeveloped, in others they were better-developed and somewhat abundant, and in still others they were in best development and abundantly extended between thyroid follicles.

The epithelial cells were polygonal. The cell bodies were larger than those of thyroid follicle cells and superficial epithelial cells of the cyst. Some of them were young parafollicular cells (Figs. 13, 14 and 15). Towards puberty, the cell bodies were further increased in size-15 to $16 \mu$ in the long diameter and 12 to $13 \mu$ in the short diameter. The nuclei were somewhat larger than those of thyroid follicle cells and superficial epithelial cells of the cyst. The chromatin reticulum was finely loose and eosinophilic. The cytoplasm was faintly eosinophilic in Zenker-formol-fixed preparations stained with Hansen's hematoxylin and eosin, and clearly and more faintly stained in Kolsterfixed preparations stained with iron-hematoxylin. In some of them, these histologic characteristics were exaggerated. The parafollicular cells appeared for the first time on three days after birth (Sato, 1959 in hamsters) (Fig. 13). They were located not only in parafollicular positions-directly upon the follicle walls, but also interfollicular spaces-between thyroid follicles and further in the epithelial walls of the cysts.

\section{Discussion}

In man, guinea pigs and rabbits, the ultimobranchial body, together with the 4th branchial pouch, appears in the 4th-5th branchial pouch complex and has a common duct-Ductus pharyngobranchialis communis, through which their cavities respectively communicate to the primitive pharynx (see Pischinger, 1937). Hamsters have neither parathyroid (4) nor thymus (4). As found in rats and mice (Sugiyama, 1940, 1942), the ultimobronchial body of this animal is found in the form of the 4th pharyngeal pouch (Figs. 1 and 2), and has its own pharyngo-branchial duct, through which its cavity communicates to the pharynx.

The observations and views concerning the relation between the developing thyroid gland and ultimobranchial body can be summarized in mammals as follows (see Sugiyama, 1971): 1. The possibility of its contribution to production of thyroid parenchyma, 2. its complete 
degeneration (disappearance within the thyroid lobe), 3. the formation of residual cysts or aciner glandular tissue, 4. reservation of determining the definitive role and fate of the ultimobranchial body despite of recognition of a close topographic relation to the developing thyroid gland and 5. the production of parafollicular cells. Gorbman (1947) wrote in mice that the thyroid structure formed from the ultimobranchial body is physiologically as well as morphologically distinguishable from the thyroid tissue derived from the mesobranchial area. According to him, atypical follicles and some large follicles of ultimobranchial orgin fail to store radioactive iodine ${ }^{131} \mathrm{I}$ in any form detectable by autoradiography. Machida et al. (1962) found the same fact in guinea pigs in embryonic life, and earlier Sato (1959) in postnatal hamsters. In the present paper, the 2., 3., and 5. items are discussed.

The embryonic development of the ultimobranchial body is divisible into 4 stages (Sugiyama, 1971 in man). This is also trua in hamsters, but these stages are very short in comparison with those of other animals (Machida et al. 1962 in guinea pigs): 1. branchial pouch stage (9 to 10 days of gestation), 2. separation stage (11 days), 3 . incorporation stage (12 to 13 days) and 4 . dissolution stage (14 to 15 days). The dissolution stage can continue further towards postnatal life.

In the branchial pouch stage, the ultimobranchial body communicates to the primitive pharynx through its own pharyngo-branchial duct. Synchronous occurrence of numerous metachromatic karyolytic droplets and frequent mitotic figures is of significance-the survival and growth of the ultimobranchial body depends upon this synchronous occurrence of degenerative and mitotic figures (Figs. 2 and 4).

In the separation stage, the pharyngobranchial duct disappears and the ultimobranchial body becomes free and approaches to the dorsal zone of the thyroid lobe (Figs. 5, 6 and 7).

In the incorporation stage, the ultimobranchial body is incorporated within the thyroid lobe (Fig. 8). The ultimobranchial body becomes irregular in shape. Usually, mitotic division increases while metachromatic karyolytic degeneration decreases. In this stage further, epithelial cell masses begin to extend from its epithelial wall (Fig. 8). This depends upon the increase of mitotic division. In the epithelial cell masses, cells with a large nucleus with faintly eosinophilic loose chromatin reticulum and a large cell body are in development-they are probably young precursors of parafollicular cells. This differentiation is more exaggerated in the dissolution stage (Figs. 9, 10, 11 and 12). Machida et al. (1962, in guinea pigs), by using Periodic acid-Schiff's and Best's stains for glycogen, failed to demonstrate whether the epithelial cell masses can survive as parafollicular 
cells or not. Kameda (1970) and earlier Godwin (1936/37) also reported the difficulty of finding parafollicular cells in embryonic dogs. However, electron microscopic studies have made it possible to distinguish parafollicular cells in late embryonic life (Ishikawa, 1965 in rats ; Lietz et al., 1971 in man). Sugiyama (1971) described the precursors of parafollicular cells in the $170 \mathrm{~mm}$ CHL human embryonic thyroid gland, with a finding similar to the present observation. Further, the present result, in combination with Sato's (1959, in hamsters), showed that young parafollicular cells appear for the first time three days after birth (Fig. 13). The data of differentiation of precursors near full term is in logical coincidence-in time relation-with the results of appearance of young parafollicular cells.

The parafollicular cells develop not only from the epithelial cell masses but also in the multi-cell-layered cyst wall. The data of postnatal dispersion of parafollicular cells-1. directly upon the follicle wall (parafollicularly) and between follicles (interfollicularly) in the neigbborhood of the cyst of the ultimobranchial body (Figs. 13, 14 and 15) and 2. further in the cyst wall-suggest that parafollicular cells. are of ultimobranchial origin and are gradually separated from the matrix by growing thyroid follicular tissue (Figs. 13, 14 and 15).

In rats and mice, the ultimobranchial body disappears often without traces in late embryonic life $(25 \mathrm{~mm}$ CRL in rats and $17 \mathrm{~mm}$ CRL. in mice) or sometimes remains as cysts (Sugiyama, 1940 and 1942). On the other hand, it has been said that, when intimately incorporated within the developing thyroid lobe, ultimobranchial tissue is indistinguishably transformed into thyroid-like vesicles which appear to function as such during periods of thyroid activity (Van Dyke 1959 in rats). In guinea pigs, soon before (16 to $18 \mathrm{~mm}$ CRL) or after incorporation (19 to $20 \mathrm{~mm}$ ) into the expanding thyroid lobe, the ultimobranchial body as a smooth thick-walled cyst begins to degenerate and later persists as irregular-shaped thinn-walled cysts near term and further after birth-sometimes as multilocular cysts (Machida, 1962). In cats, the ultimobranchial body becomes cysts through reticulation of the epithelial wall or a few intrathyroid thymic islets through lymphocyte infiltration (Terada, 1954). In opossums, the ultimobranchial body appears as a nodule consisting of large and small vesicles in the thyroid tissue (Adams, 1955). In dogs, the ultimobranchial body remains as cysts of stratified epithelium containing ciliated cells (Tashiro, 1963) in puppies. Earlier, Godwin (1936/37) described that the postnatal ultimobranchial body is able to produce gray cells-parafollicular cells.

As found in guinea pigs, the ultimobranchial body in postnatal hamsters remains as a single- or double-cell-layered thinn-walled cyst, usually with more or less abundant epithelial cell masses to develop 
parafollicular cells, rarely with accessory cysts (Fig. 16), and is generally not found as a nodule of vesicles.

\section{Summary}

The embryonic and postembryonic development of the hamster ultimobranchial body was studied in relation to the differentiation of parafollicular cells. The results were as follows :

The embryonic development is divisible into 4 stages : 1 . branchial pouch stage (9 to 10 days of gestation)-a stratified epithelial pocket communicating with the pharynx in the form of the 4th branchial pouch, 2. separation stage (11 days)-an independent stratified epithelial cyst, without communicating to the pharynx, 3 . incorporation stage (12 to 13 days)-its inclusion within the thyroid lobe, beginning production of epithelial cell masses from the cyst and subsequent fusion with thyroid primordial tissue and 4. dissolution stage (14 to 15 days) contains increased development of the epithelial cell masses. This stage continues towards postnatal life, being further dissolved into different components as main and accessory cysts with or without ciliated cells and goblet cells.

The parafollicular cells differentiate from the epithelial cell masses. The epithelial cells of the epithelial cell masses become precursorsthose with a large nucleus and a large cell body and are typical in appearance for the first time on three days after birth and grow in size towards puberty.

\section{Acknowledgements}

The authors wish to express their sincere gratitude to Assistant Professer Dr. Tamiko Sato in Department of Pathology, Downstate Medical Center State University of New York for her kind permission to use her valuable collections of histological preparations of developing ultimobranchial bodies of hamsters for this study.

\section{Literature cited}

Adams, W.E.: The carotid sinus complex, “parathyroid" III and thymoparathyroid bodies, with special referece to Australian opossum, Trichosurus vulpecula. Am. J. Anat. $97:$ 1-58, 1955.

Copp, D. H., Cockeroft, D. W. and Kueh, Y.: Calcitonin from ultimobranchial glands of $\operatorname{dog}$ fish and chickens. Science 158: 924-925, 1967.

and Parkes, C. O.: Parathyroid hormone and thyrocalcitonin (Calcitonin). Extraction of calcitonin from ultimobranchial tissue (ed. by R. V. Talmage and L. F. Bélanger). p. 74-82, 1968, Amsterdam: Excerpta Medica Foundation. 
Dyke, J. H. van: The ultimobranchial body. Comparative Endocrinology (ed. by A. Gorbman), p. 320-339, 1959, New York: J. Wiley \& Sons.

Godwin, M. Cr.: Complex IV in the dog with special emphasis on the relation of the ultimobranchial body to interfollicular cells in the postnatal thyroid gland. Am. J. Anat. 60 : 299-339, 1936/37.

Gorbman, A.: Functional and morphological properties in the thyroid gland, ultimobranchial body, and persisting ductus pharyngiobranchialis IV of an adult mouse. Anat. Rec. 98 : 93-102, 1947.

Ishikawa, K.: Electron microscopical studies of the ultimobranchial body of the rat in embryonic life, with special emphasis on its fate-the relation to the thyroid tissue and parafollicular cells. Okajimas Fol. anat. jap. $41: 313-335,1965$.

Kameda, Y.: Two variants of parafollicular cell groups in the dog thyroid glands. Acta anat. Nippon. $45: 16,1970$.

Lietz, H., J. Wöhler and H. Pomp: Zur Entwicklung und Ultrastruktur der embryonalen Schilddrüse des Menschen Z. Zellforsch. 113: 94-110, 1971.

Machida, Y. and Sugiyama, S.: The fate of the ultimobranchial body of the guinea pig and its relation to thyroid development. Okajimas Fol. anat. jap 38 : 7387, 1962.

Matsuzawa, T.: Experimental morphological studies on the parafollicular cells of the rat thyroid gland, with special reference to the source of thyrocalcitonin. Arch. histol. jap. $27: 521-544,1966$.

- and Kurosumi, K.: Morphological changes in the parafollicular cells of the rat thyroid glands after administration of calcium shown by electron microscopy. Nature (Lond.) 213: 927-928, 1967.

Moseley, J. M., Matthews, E. W., Breed, R.H., Galante, L., Tse, A. and MacIntyre, I. : The ultimobranchial of calcititonin. Lancet $1968 \mathrm{I}, 108-110$.

Nonidez, J.F.: The origin of the "parafollicular" cell, a second epithelial component of the thyroid gland of the dog. Am. J. Anat., 49: 479-505, 1932a.

: Further observations on the parafollicular cells of the mammalian thyroid. Anat. Rec. 53 : 339-347, $1932 \mathrm{~b}$.

- : The "parenchymatous" cell of BABER, "protoplasma-reichen Zellen" of HÜRTHLE, and the "parafollicular" cells of mammalian thyroid. Anat. Rec., 56 : 131-141, 1933.

Pearse, A. G. E. and Carvalheira, A. F.: Cytochemical evidence for an ultimobranchial origin of rodent thyroid C cells. Nature (Lond.) $214:$ 929-930, 1967.

Pischinger, A.: Kiemenanlagen und ihre Schicksale bei Amnioten-Schilddrüse und epitheliale Organe der Pharynxwand bei Tetrapoden. Bolk-Göpperts Handbuch der vergleichenden Anatomie der Wirbeltiere, Bd. 3, S. 279-348, 1937. Berlin \& Wien Urban \& Schwarzenberg.

Raymond, N.: The occurrence of parafollicular cells in the thyroid of the rabbit. Anat. Rec. 53 : 355-365, 1932.

Sato, T.: The postnatal histogenesis of the thyroid gland of the golden hamster (Cricetus auratus). Okajimas Fol. anat. jap. 33 : 225-253, 1959.

Sugiyama, S.: The fate of the ultimobranchial body of the albino rat with special reference to the formation of the thyroid gland. Okajimas Fol. anat. jap. 19 : 333-341, 1940.

- : The development and the fate of the ultimobranchial body in the mouse with special emphasis on its relation to the thyroid gland. Jap. J. med. Sci., pt. 1 Anat. 9 : 153-168, 1942.

-: Studies of the postnatal histogenesis of the thyroid gland of the guinea pig. I. The thyroid cells (follicle cells and parafollicular cells). Anat. Rec. 120 : 368-378, 1954. 
-_ : The embryology of the human thyroid gland including ultimobranchial body and others related. Ergeb. Anat. Entwickl.-Gesch. Bd. 44 H. 2 ! p. 1-112, 1971. Tashiro, M.: Electron microscopic observations of the cyst of ultimobranchial origin found in the thyroid gland of a dog. Nagoya J. Med. Sci. 25 : 159-163, 1963.

Terada, T.: An embryological study on the thyroid, particularly on its relation to the ultimobranchial body and parathyroid and thymus in and outside it, in the cat. Acta med. $24: 81-106,1954$.

Young, B. A., Care, A. D. and Duncan, T.: Some observations on the light cells of the thyroid gland of the pig in relation to thyrocalcitonin production. J. Anat. (Lond.) $102: 275-288,1968$. 


\section{PLATES}




\section{Explanation of Plate Figures}

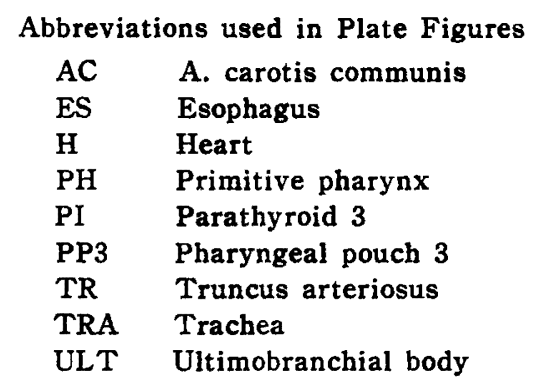

\section{Plate I}

1. 9 days of gestation. The third branchial pouch, as a triangular pocket and the ultimobranchial body, as an ovoid pocket, are seen. Between the both, the 4th branchial arch artery, and behind the ultimobranchial body, the 6th branchial arch artery, are found. Sagittal section. Zenker-formol. Hematoxylin and eosin. $\times 52$. 2. The detail of Fig. 1. The ultimobranchial body is composed of stratified epithelium, in which mitotic figures (arrows) and karyolytic degenerative figures are seen. Mesenchymal tissue surrounding the ultimobranchial body is not arranged in layers. $\times 520$.

3. 10 days of gestation. The ultimobranchial body, as a stratified epithelial pocket, is situated upon the heart and far from the thyroid primordium which is found in the front of the Truncus arteriosus. Sagittal section. Zenker-formol. Hematoxylin and eosin. $\times 52$.

4. The detail of Fig. 3. The ultimobranchial body is composed of stratified epithelium, in which mitotic (arrows) and karyolytic degenerative figures are seen. Surrounding mesenchymal tissue becomes denser in arrangement than before. $\times 520$.

5. 11 days ( 10 days and half) of gestation. The ultimobranchial body, as an ovoid body is just behind the thyroid primordium. Sagittal section. Hematoxylin and eosin. $\times 52$.

6. The detail of Fig. 5. The ultimobranchial body is a stratified epithelial thickwalled cyst containing cell detrituses in its cavity and is approaching to the thyroid primordium. Sagittal section. Zenker-formol. Hematoxylin and eosin. $\times 520$. Karyolytic degenerative figures are now decreasing in number.

7. 11 days of gestation. The ultimobranchial body is now just before incorporation within the thyroid lobe-just behind the dorsal zone of the cranial part of the thyroid lobe. Transverse section. Zenker-formol. Hematoxylin and eosin. $\times 130$.

8. 12 days of gestation. The ultimobranchial body is now being incorporated within the thyroid lobe. Its stratified epithelial wall is directly fused with thyroid primordial tissue. In the cavity, cell detrituses are found. The parathyroid (3) is seen. Transverse section. Zenker-formol. Hematoxylin and eosin. $\times 260$. 


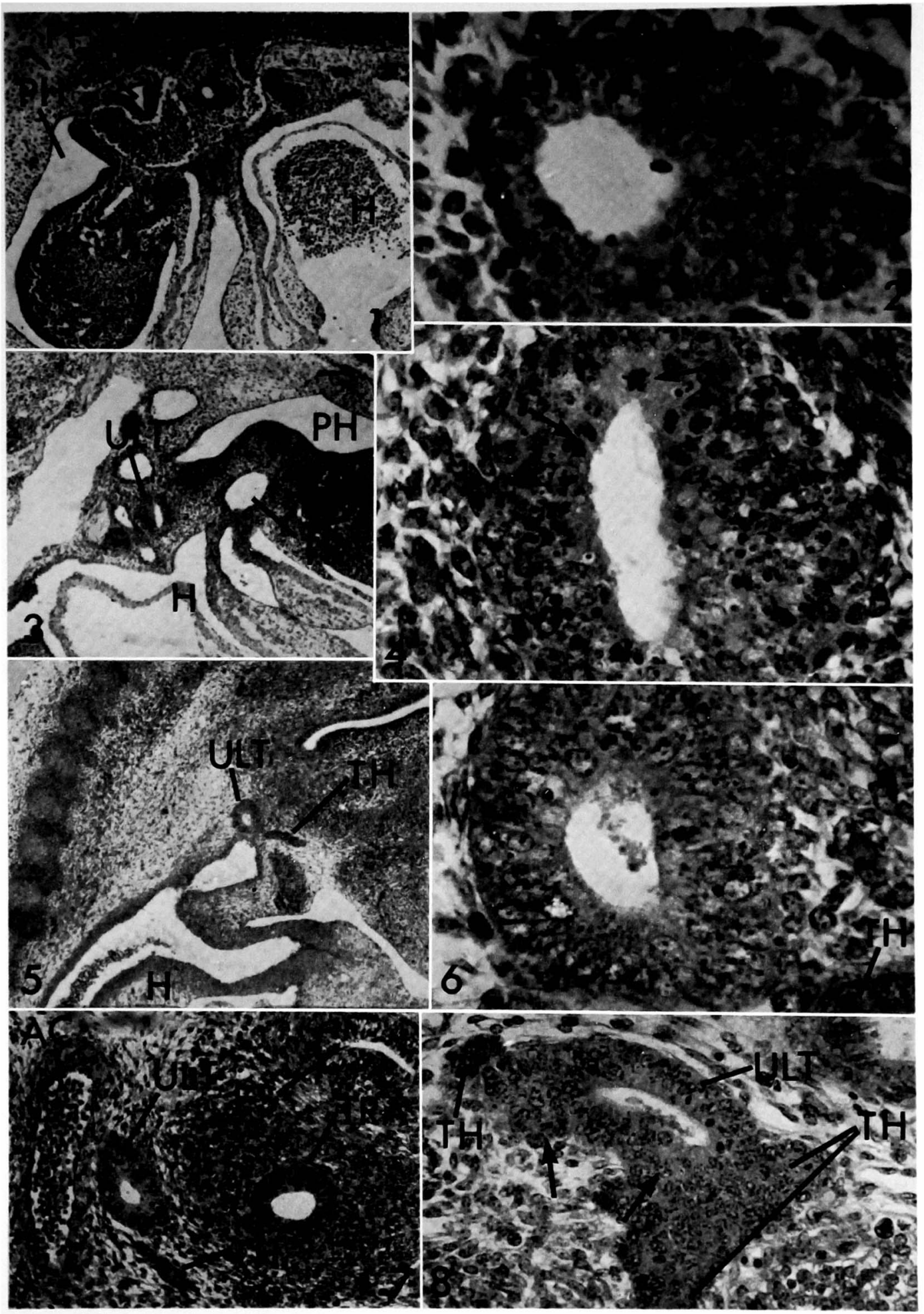




\section{Plate II}

9. 14 days of gestation. The ultimobranchial body is now completely incorporated with the thyroid lobe and is surrounded with primitive thyroid follicular tissue. From the stratified epithelial wall, cell conglomerates are produced and extending between the thyroid primitive follicular tissues. Transverse section. Hematoxylin and eosin. $\times 260$.

10. The detail of Fig. 9. The cell conglomerates are producing from the stratified epithelial wall and epithelial cells with a large chromatin-poor nucleus and a large cell body (arrows) are developing here. The nucleus and cell body are larger than those of primitive follicle cells and epithelial cells lining directly the cavity. $\times 520$. 11. 15 days of gestation. The ultimobranchial body is an epithelial cyst with a split-form cavity, of which the epithelium is partly single-cell-layered and partly multi-cell-layered. From here, cell conglomerates containing epithelial cells with a large nucleus and a large cell body, precursors of parafollicular cells are developing. Numerous thyroid follicles are seen around the ultimobranchial body. Transverse section. Zenker-formol. Hematoxylin and eosin. $\times 260$.

12. The detail of Fig. 11. The epithelial cells with a large nucleus and a large cell body are developing in the cell conglomerates and further they are now dispersed between follicles and directly upon the follicle walls. $\times 520$.

13. Three days after birth. The ultimobranchial body is seen as an epithelial cyst with a split-form cavity. In the epithelial wall and in the neighborhood, epithelial cells with a large chromatin-poor nucleus and a clear large cell body (arrows) are seen between follicles and directly upon follicles. They are young parafollicular cells. Transverse section. Kolster. Iron hematoxylin. $\times 520$.

14 and 15. 45 days after birth. The ultimobranchial body is seen as an epithelial cyst in the left upper angle of Fig. 14. In the neighborhood of the ultimobranchial body, typical parafollicular cells found between follicles and directly upon follicles. Tney are clear epithelial cells with a large chromatin-poor and a clear large cell body. The chromatin reticulum of their nucleus is fainter than that of follicle cells and epithelial cells lining directly the cyst cavity. $\times 260$ and $\times 520$. Transverse section. Kolster. Iron Hematoxylin.

16. 60 days after birth. The ultimobranchial body is found as an irregular-shaped epithelial cyst. The epithelium is variable-partly single columnar or cubical and partly stratified squamous or stratified columnar. The cavity contains many cell detrituses. Transverse section, Zenker-formol. Hematoxylin and eosin. $\times 260$. 


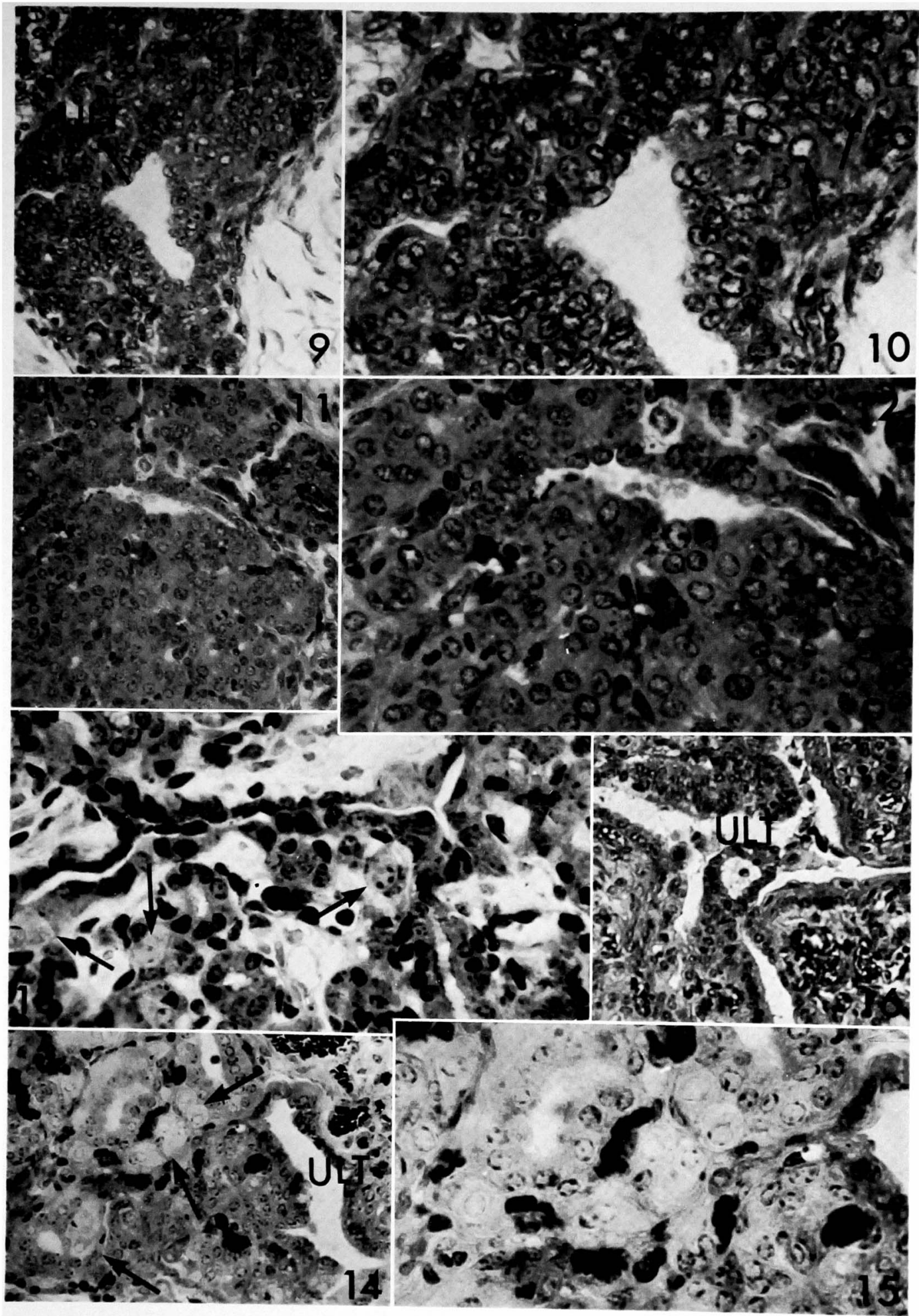

I. Takagi, K. Yamada and S. Sugiyama 